\title{
Total matrix metalloproteinase-8 serum levels in patients labouring preterm and patients with threatened preterm delivery
}

\author{
Paweł Kuć ${ }^{1}$, Adam Lemancewicz ${ }^{1}$, Piotr Laudański ${ }^{1}$, Małgorzata Krętowska ${ }^{2}$, \\ Tadeusz Laudański ${ }^{1}$
}

${ }^{1}$ Department of Perinatology, Medical University of Białystok, Poland

${ }^{2}$ Institute of Informatics, Technical University of Białystok, Poland

\begin{abstract}
Preterm labour and prematurity are still a main cause of perinatal morbidity nowadays. The aim of our study was to assess the role of MMP-8 as a predictive marker of preterm delivery. Four groups of patients were involved to the study: I - pregnant women at 24-34 weeks of gestation with any symptoms of threatened preterm labour; II - threatened preterm labour patients between 24-34 weeks of gestation; III - preterm vaginal delivery patients; IV - healthy term vaginal delivery patients. Serum concentration of total MMP-8 was measured using two enzyme-linked immunosorbent assays. There were no significant differences in the median concentrations of total MMP-8 between physiological pregnancy and threatened preterm labour patients with existing uterine contractility. No significant differences of total MMP-8 were either found between healthy term and preterm labouring patients. The studies on a larger population are needed to reject the hypothesis that preterm labour is connected with increased MMP-8 plasma concentrations of women in preterm labour and threatened preterm delivery.
\end{abstract}

Keywords: preterm labour; threatened preterm delivery; MMP-8; ELISA.

\section{Introduction}

Matrix metalloproteinases (MMPs) represent an interesting family of zinc-dependent enzymes that belong to the class of metalloproteinases, which are essential effectors of developmental processes, balanced by their tissue inhibitors of metalloproteinases (TIMPs). They are participating in the processes of cell migration, cell proliferation, apoptosis and tissue morphogenesis regulating the function of biologically active molecules. The MMPs also fulfill an important role in endothelial cell invasion, angiogenesis and in tumor progression [1-5].

The degradative matrix metalloproteinase play an important role in remodeling a number of tissues, and because they are only enzymes capable of degrading the components of the extracellular matrix they are likely to play a role in the remodeling of the collagen rich, extracellular matrix of the fetal membranes, including the

Correspondence: P. Kuć, Dept. of Perinatology; Medical University of Białystok, Sklodowskiej-Curie 24a Str., 15-276 Białystok, Poland; tel/fax: (+ 4885) 7468352, e-mail: kucp@poczta.fm marked disruption of the connective tissue layers in the cervical area [6,7].

Metalloproteinase- 8 , also known as collagenase- 2 or neutrophil collagenase, which common substrates are: collagens I-III, $\alpha_{2}$-macroglobulin, $\alpha_{1}$-proteinase inhibitor, C1q, fibrinogen, substance P. Like most MMPs, MMP-8 is secreted as an inactive pro-enzyme that needs to be activated before it can exert its function. This pro-form of MMP-8 contains an N-terminal prodomain with the cysteine residue that interacts with the $\mathrm{Zn}^{2+}$ ion at the active site to block all proteolytic activity. Only by disrupting this mechanism can the proenzyme be converted into an active protease [5].

The aim of this study was to measure the concentration of a total forms of MMP-8 in serum during physiological pregnancy, threatened preterm labour patients, as well as in preterm and term labouring patients, to assess the role of MMP-8 in pathogenesis of preterm labour.

\section{Materials and methods}

Patients. Patients were divided into four groups: I $(n=25)-$ women at gestational age 24-34 weeks of pregnancy without any 
Table 1. Clinical characteristics of four groups of studied patients

\begin{tabular}{|l|c|c|c|c|}
\hline & $\begin{array}{c}\text { Group I } \\
\mathrm{n}=25\end{array}$ & $\begin{array}{c}\text { Group II } \\
\mathrm{n}=16\end{array}$ & $\begin{array}{c}\text { Group III } \\
\mathrm{n}=22\end{array}$ & $\begin{array}{c}\text { Group IV } \\
\mathrm{n}=35\end{array}$ \\
\hline Matcmal age $(\operatorname{mean} \pm \mathrm{SD})$ & $28.2 \pm 3.1$ & $31.6 \pm 3.4$ & $31.5 \pm 1.1$ & $28.1 \pm 2.5$ \\
\hline Gestational age $(\operatorname{mean} \pm \mathrm{SD})$ & $31.9 \pm 2.3$ & $29.4 \pm 3.9$ & $32.8 \pm 1.3$ & $31.0 \pm 4.2$ \\
\hline
\end{tabular}

Group I - patients at gestational age without any symptoms of preterm labour; Group II - threatened preterm labour patients;

Group III - preterm vaginal delivery; Group IV - term vaginal delivery

Table 2. The mean values ( SD) total MMP-8 serum concentrations in each study group

\begin{tabular}{|l|c|c|c|c|c|}
\hline & $\begin{array}{c}\text { Group I } \\
\text { Mcan } \pm \mathrm{SD}\end{array}$ & $\begin{array}{c}\text { Group II } \\
\text { Mcan } \pm \mathrm{SD}\end{array}$ & $\begin{array}{c}\text { Group III } \\
\text { Mcan } \pm \mathrm{SD}\end{array}$ & $\begin{array}{c}\text { Group IV } \\
\text { Mcan } \pm \mathrm{SD}\end{array}$ & $\mathrm{p}$ value \\
\hline lolal MMP-8 ng/mL & $0.396 \pm 1.017$ & $0.135 \pm 0.061$ & $0.131 \pm 0.036$ & $0.238 \pm 0.026$ & $\mathrm{p}=0.21$ \\
\hline
\end{tabular}

Group I - patients at gestational age without any symptoms of preterm labour; Group II - threatened preterm labour patients;

Group III - preterm vaginal delivery; Group IV - term vaginal delivery

symptoms of preterm labour (physiological pregnancy); II ( $\mathrm{n}=16)$ - threatened preterm labour patients with uterine contractility at gestational age 24-34 weeks of pregnancy with intact fetal membranes; III $(n=22)$ - preterm vaginal delivery patients with preterm premature rapture of fetal membranes; IV $(n=35)$ - control term vaginal delivery patients with premature rapture of fetal membranes. Prior consent for the study was obtained from the Local Bioethical Committee of Medical University of Białystok, which accepted study protocol. Gestational age of patients was calculated according to the date of last menstrual period confirmed by first trimester ultrasound examination. The study excluded the patients who had administered the antibiotic therapy within the last 3 weeks, multiple pregnancy, chorioamnionitis, cervical cerclage, vaginal bleeding, placenta praevia, diabetes and renal disease in pregnancy. All labouring patients and threatened preterm labour patients had regular uterine contractility at least 3 hours before obtained blood sample. All patients were primiparas. In all preterm and term labouring patients, premature rapture of fetal membranes have place in the first stage of labour and blood samples were obtained after ruptures of membranes. The time from premature rapture of fetal membranes to delivery was not longer than 6 hours. Clinical characteristics of patients are shown in Table 1.

MMP-8 concentration assessment. The total MMP-8 serum levels were measured in plasma samples with the using enzymelinked immunosorbent assays (MMP-8, Human, Biotrak ELISA System, Amersham Biosciences).

Statistical analysis. For statistical analysis comparison of mean values of total MMP- 8 between four groups of patients was performed by analysis of variance (ANOVA). The statistical analysis was performed using PRISM (GraphPad, US) and SAS STAT (SAS Institute, US) packages. The 0.05 significance level was applied.

\section{Results}

No statistically significant differences in the median serum concentrations of total MMP-8 was found between four studied groups of patients $(\mathrm{p}=0.046)$. (Fig. 1). The mean values of MMP-8 concentrations in each study group and standard deviations are presented in Table 2, but these results were not statistically significant $(\mathrm{p}=0.21)$.

\section{Discussion}

Despite of recent development in perinatology and prenatal treatment, the mechanisms of induction of preterm uterine contractility remains still unknown. From the other site, the costs of prenatal and neonatal care are still rising. Therefore, it is important to find non-invasive and non-expensive method allow to predict preterm delivery [8-11].

Approximately $50 \%$ of cases of preterm labour are associated with preterm premature rapture of fetal membranes (pPROM). In the pathogenesis of preterm labour, several interrelated mechanisms are included. Firstly, production and release of inflammatory cytokines may lead to increased prostaglandin secretion $[5,12]$. Secondly, pPROM and its consequence - preterm labour may be initiated by many factors such as infection, drugs or others [13]. There is also an evidence sup-

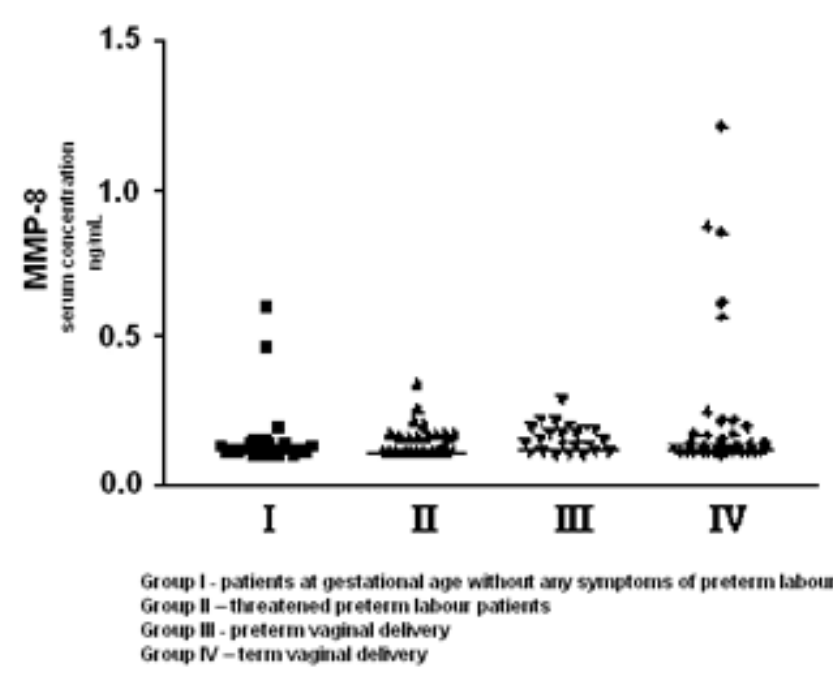

Fig. 1. Median values of total MMP-8 concentrations in studied groups $(\mathrm{p}=0.046)$. 
porting the implication of matrix metalloproteins and their depredating enzymes in the processes of preterm and term labour as well as that of pPROM [13-15].

A programmed collagenolytic remodeling process exists in fetal membranes during pregnancy to accommodate them to the increasing uterine pressure and volume. This process is mediated by metalloproteinases. There are a number of regulatory mechanisms that can influence on the MMPs' dependent extracellular matrix degradation. Regulation occurs at the transcriptional level, translational level, post-translational level (activation of zymogen forms of MMPs) and at the tissue level by specific regulators known as the tissue inhibitors of metalloproteinases (TIMPs). A balanced activity between MMPs and TIMPs has been documented during tissue remodeling in several systems. The role of MMPs in human labour and pPROM has been a subject of considerable study over the last decade. Increased collagenolysis, a drop in the collagen content of the membranes and activation of MMPs have been documented during active stage of labour [13-16].

Research studies have already confirmed a significant role of many MMPs in mechanism of labour. The expression of MMP-1, MMP-2, MMP-3, MMP-9, MMP-10, MMP-11 mRNA was confirmed in amnion and chorion in preterm as well as in term patients. It was also investigated that amniotic fluid concentration of MMP-1, MMP-2 and MMP-3 increase during the labour [16-21]. MMP-7 and MMP-8 mRNA were not found in amniochorionic tissue, but MMP-8 was detected in the amniotic fluid. In amniotic fluid concentration of MMP-8 also raised during the active stage of labour [21-23]. There was not found research studies confirming the role of MMP-12 and MMP-13 with pPROM patients.

The elevation of MMP-14 concentration and decrease in TIMP-2 concentration, resulting in activation of MMP-2 [23]. Maymon et al. [19] reported that amniotic concentrations of active forms of MMP-2 were significantly lower in patients with spontaneous labour at term, term and preterm rupture of membranes as well as in intrauterine infection connected with preterm premature rupture of fetal membranes. The participation of these metalloproteinases in the mechanisms of labour, rupture of membranes and intrauterine infection it seem to be clear. The activity of metalloproteinase- 2 is also increased in amniotic fluid in preterm premature rupture of membranes [23].

Koscica et al. study [12] on animal model confirmed the role of metalloproteinases MMP-1, MMP-2, MMP3, MMP-8 and MMP-9 in the preterm parturition process complicated by inflammatory factors. They hypothesized that administration of a MMP inhibitor would reduce the rate of inflammation-mediated preterm delivery and prolong gestation in a mouse model.
Biggio et al. [24] showed that, the overall distribution of MMP-8 concentration in amniotic fluid was comparable in preterm patients with premature rupture of membranes and in term delivered patients. One fourth part of patients with pPROM had a MMP-8 concentration above the 90th percentile, in comparison with only $10 \%$ of term controls. The overall distribution of mid trimester amniotic fluid, MMP-8 concentration did not differ between women with pPROM and delivered at term.

Yonemoto et al. [25] confirmed that increased matrix metalloproteinase (MMP)-9 activity is associated with term birth, preterm birth and premature rupture of membranes. MMP-9 pro-enzyme activities in the amnion increased significantly with labour at term, and were higher than at preterm labour. There were no changes in chorion MMP-9 activity between studied groups. They also suggested MMP-2 may be another regulator of membrane rupture and other labour-associated mechanisms at term parturition, bur its need more clinical trials.

According to Maymon et al. study [26], authors showed a role of matrix metalloproteinase- 8 as a sensitive marker of intrauterine infection and preterm labour in patients with intact membranes. The rate of preterm delivery was $54 \%$ and that of intra-amniotic infection was $9.2 \%$. The median amniotic fluid matrix metalloproteinase- 8 concentration was more than 50fold higher in patients with intra-amniotic infection than in patients without. The matrix MMP-8 amniotic fluid concentrations were significantly higher in patients who delivered preterm than in patients who delivered at term. After exclusion of patients with intra-amniotic infection, patients who delivered preterm had a significantly higher median amniotic fluid matrix metalloproteinase-8 than patients who delivered at term. An amniotic fluid MMP-8 concentration cut-off level $>30 \mathrm{ng} / \mathrm{mL}$ was an predictor factor of increased neonatal morbidity.

At another study by Maymon et al. [27] authors investigated, if MMP-8 amniotic fluid concentration changed in preterm and term labour according to influence of premature rupture of fetal membranes or intraamniotic infection. Spontaneous rupture of membranes in preterm patients was associated with elevated amniotic fluid MMP-8 concentrations. Microbial invasion of the amniotic cavity was associated with a significantly higher MMP-8 concentration in preterm patients with intact membranes, as well as ruptured membranes.

In all studies presented above, the invasive diagnostic amnicenthesis procedure was used to asses the MMPs concentration in the amniotic fluid. This procedure is strictly connected with the increased risk of materno-fetal complications. Therefore, it is so important to find non-invasive diagnostic method being 
helpful to find a sensitive predictive marker of preterm labour. It seems to be in value to look for the predictive factors in serum, urine or cervical mucus.

In our previous studies $[28,29]$ we evaluate the concentrations of active and total MMP-2 and TIMP-2 in serum and urine in preterm labour patients at 24-36 weeks of pregnancy, threatened preterm labour patients at 24-36 weeks of pregnancy and patients delivered at term. No significant differences in the concentrations of active MMP-2, total MMP-2 and TIMP-2 were found between studied groups

Makrakis et al. [30] reported that plasma and urine MMP-9 levels were significantly higher and serum and urine TIMP-1 were significantly lower in patients with spontaneous uterine contractions term and preterm delivering patients, in comparison to nonlabouring patients. According to authors' hypothesis the elevated plasma and urine concentration of MMP9 could possibly identify the inevitable progress of uterine contractility to final preterm labour.

Sorokin et al. [31] evaluated the maternal serum concentration of interleukin-6 (IL-6), C-Reactive Protein (CRP), and matrix metalloproteinase-9 (MMP9) as potential predictive factors of preterm delivery. Among the patients, who have any symptoms of threatened preterm delivery and intact membranes, only maternal serum concentrations of IL-6 and CRP, but not MMP-9 were associated with higher risk of preterm delivery $<32$ weeks.

Botsis et al. [32] assessed the value of plasma MMP-9 levels in predicting the progress of threatened preterm labour to preterm delivery within 7 days of presentation together with the ultrasonographic measurement of cervical length. Study showed that plasma MMP-9 levels could possibly serve as a predictive factor for the progress of threatened preterm labour to true preterm labour and delivery within 7 days of presentation, along with the ultrasound evaluation of cervical length.

Choi et al. [33] investigated the changes of matrix metalloproteinase-9 (MMP-9) in cervicovaginal fluid during pregnancy and its association with term parturition. Cervicovaginal MMP-9 concentration did not change significantly with advancing gestation until 37 weeks, and significantly increased after 37 weeks. Cervicovaginal MMP-9 levels were similar in non-labouring pregnant women, spontaneous term labour patients and premature rupture of membranes patients at term.

Considering the difficulties in finding ideal predictive marker of preterm delivery, as well as differentiate biochemical activities of MMPs, we may conclude, that the studies on the larger population are needed to reject the hypothesis that preterm labour is connected with increased MMP-8 plasma concentrations of women in preterm labour and threatened preterm delivery.

\section{References}

[ 1] Kenagy RD, Vergel S, Mattsson E, Bendeck M, Reidy MA, Clowes AW. The role of plasminogen, plasminogen activators, and matrix metalloproteinases in primate arterial smooth muscle cell migration. Arterioscler Thromb Vasc Biol. 1996;16(11):1373-1382.

[2] Lo EH, Wang X, Cuzner ML. Extracellular proteolysis in brain injury and inflammation: role for plasminogen activators and matrix metalloproteinases. $J$ Neurosci Res. 2002; 69(1):1-9.

[3] Nisato RE, Hosseini G, Sirrenberg C, et al. Dissecting the role of matrix metalloproteinases (MMP) and integrin alpha(v)beta3 in angiogenesis in vitro: absence of hemopexin $\mathrm{C}$ domain bioactivity, but membrane-Type 1-MMP and alpha(v)beta3 are critical. Cancer Res. 2005;65(20):93779387.

[ 4] Pepper MS. Role of the matrix metalloproteinase and plasminogen activator-plasmin systems in angiogenesis. Arterioscler Thromb Vasc Biol. 2001;21(7):1104-1117.

[5] Visse R, Nagase H. Matrix metalloproteinases and tissue inhibitors of metalloproteinases: structures, function, and biochemistry. Circ Res. 2003;92:827-839.

[6] Xu P, Alfaidy N, Challis JR. Expression of matrix metalloproteinase (MMP)-2 and MMP-9 in human placenta and fetal membranes in relation to preterm and term labour. $J$ Clin Endocrinol Metab. 2002;87(3):1353-1361.

[7] Fortunato SJ, Menon R, Lombardi SJ. Collagenolytic enzymes (gelatinases) and their inhibitors in human amniochorionic membrane. Am J Obstet Gynecol. 1997;177(4): 731-741.

[ 8] ACOG. Premature rupture of membranes. American College of Obstetricians and Gynecologists. Washington (DC). ACOG practice bulletin. 2007, pp. 80 .

[ 9] Di Renzo GC, Roura LC. Guidelines for the management of spontaneous preterm labor. J Perinat Med. 2006;34(5):359366.

[10] Goldenberg RL. The management of preterm labor. Obstet Gynecol. 2002;100(5 Pt 1):1020-1037.

[11] Lopez Bernal A. Mechanisms of labour--biochemical aspects. Bjog. 2003;110 Suppl 20:39-45.

[12] Koscica KL, Ananth CV, Placido J, Reznik SE. The effect of a matrix metalloproteinase inhibitor on inflammation-mediated preterm delivery. Am J Obstet Gynecol. 2007;196(6):551553.

[13] Fortunato SJ, Menon R, Bryant C, Lombardi SJ. Programmed cell death (apoptosis) as a possible pathway to metalloproteinase activation and fetal membrane degradation in premature rupture of membranes. Am J Obstet Gynecol. 2000; 182(6):1468-1476.

[14] Fortunato SJ, Menon R. Distinct molecular events suggest different pathways for preterm labor and premature rupture of membranes. Am J Obstet Gynecol. 2001;184(7):1399-1405; discussion 1405-1396.

[15] Maymon E, Romero R, Pacora P, et al. Evidence for the participation of interstitial collagenase (matrix metalloproteinase 1) in preterm premature rupture of membranes. Am J Obstet Gynecol. 2000;183(4):914-920.

[16] Menon R, Fortunato SJ. The role of matrix degrading enzymes and apoptosis in rupture of membranes. J Soc Gynecol Investig. 2004;11(7):427-437.

[17] Qin X, Chua PK, Ohira RH, Bryant-Greenwood GD. An autocrine/paracrine role of human decidual relaxin. II. Stromelysin-1 (MMP-3) and tissue inhibitor of matrix metalloproteinase-1 (TIMP-1). Biol Reprod. 1997;56(4):812-820.

[18] Qin X, Garibay-Tupas J, Chua PK, Cachola L, Bryant-Greenwood GD. An autocrine/paracrine role of human decidual relaxin. I. Interstitial collagenase (matrix metalloproteinase- 
1) and tissue plasminogen activator. Biol Reprod. 1997;56(4): 800-811.

[19] Maymon E, Romero R, Pacora P, et al. Evidence of in vivo differential bioavailability of the active forms of matrix metalloproteinases 9 and 2 in parturition, spontaneous rupture of membranes, and intra-amniotic infection. Am $\mathrm{J}$ Obstet Gynecol. 2000;183(4):887-894.

[20] Vadillo-Ortega F, Gonzalez-Avila G, Furth EE, et al. 92-kd type IV collagenase (matrix metalloproteinase-9) activity in human amniochorion increases with labor. Am J Pathol. 1995;146(1):148-156.

[21] Athayde N, Romero R, Gomez R, et al. Matrix metalloproteinases-9 in preterm and term human parturition. $J$ Matern Fetal Med. 1999;8(5):213-219.

[22] Fortunato SJ, Menon R, Lombardi SJ. Stromelysins in placental membranes and amniotic fluid with premature rupture of membranes. Obstet Gynecol. 1999;94(3):435-440.

[23] Fortunato SJ, Menon R, Lombardi SJ. MMP/TIMP imbalance in amniotic fluid during PROM: an indirect support for endogenous pathway to membrane rupture. $J$ Perinat Med. 1999;27(5):362-368.

[24] Biggio JR, Jr., Ramsey PS, Cliver SP, Lyon MD, Goldenberg RL, Wenstrom KD. Midtrimester amniotic fluid matrix metalloproteinase-8 (MMP-8) levels above the 90th percentile are a marker for subsequent preterm premature rupture of membranes. Am J Obstet Gynecol. 2005;192(1):109-113.

[25] Yonemoto H, Young CB, Ross JT, Guilbert LL, Fairclough RJ, Olson DM. Changes in matrix metalloproteinase (MMP)2 and MMP-9 in the fetal amnion and chorion during gestation and at term and preterm labor. Placenta. 2006;27(67):669-677.

[26] Maymon E, Romero R, Chaiworapongsa T, et al. Amniotic fluid matrix metalloproteinase- 8 in preterm labor with intact membranes. Am J Obstet Gynecol. 2001;185(5):1149-1155.
[27] Maymon E, Romero R, Pacora P, et al. Human neutrophil collagenase (matrix metalloproteinase 8 ) in parturition, premature rupture of the membranes, and intrauterine infection. $\mathrm{Am}$ J Obstet Gynecol. 2000;183(1):94-99.

[28] Lemancewicz A, Laudański P, Kuć P, Pierzyński P, Krętowska M, Urban J. Matrix metalloproteinase-2 and tissue inhibitor of metalloproteinase-2 urine levels in preterm labouring patients. Arch Perinatal Med. 2007;13(2):50-52.

[29] Lemancewicz A, Laudański P, Kuć P, Pierzyński P, Krętowska M, Urban J. Matrix metalloproteinase-2 and tissue inhibitor of metalloproteinases-2 plasma levels in preterm labouring patients. Arch Perinat Med. 2007;12(3):33-35.

[30] Makrakis E, Grigoriou O, Kouskouni E, et al. Matrix metalloproteinase- 9 and tissue inhibitor of metalloproteinase- 1 in plasma/serum and urine of women during term and threatened preterm labor: a clinical approach. J Matern Fetal Neonatal Med. 2003;14(3):170-176.

[31] Sorokin Y, Romero R, Mele L, et al. Maternal Serum Interleukin-6, C-Reactive Protein, and Matrix Metalloproteinase-9 Concentrations as Risk Factors for Preterm Birth $<32$ Weeks and Adverse Neonatal Outcomes. Am J Perinatol. 2010.

[32] Botsis D, Makrakis E, Papagianni V, et al. The value of cervical length and plasma proMMP-9 levels for the prediction of preterm delivery in pregnant women presenting with threatened preterm labor. Eur J Obstet Gynecol Reprod Biol. 2006;128(1-2):108-112.

[33] Choi SJ, Jung KL, Oh SY, Kim JH, Roh CR. Cervicovaginal matrix metalloproteinase-9 and cervical ripening in human term parturition. Eur J Obstet Gynecol Reprod Biol. 2009; 142(1):43-47.

Submitted: 13 March, 2010 Accepted after reviews: 22 June, 2010 